\title{
Optimal management of familial hypercholesterolemia: treatment and management strategies
}

This article was published in the following Dove Press journal:

Vascular Health and Risk Management

I December 2010

Number of times this article has been viewed

Mohammad Hassan Nemati ${ }^{\prime}$

Behrooz Astaneh ${ }^{2}$

'Cardiac Surgery Department, Faghihi Hospital, ${ }^{2}$ Vice Chancellor for Research Department, Shiraz University of Medical Sciences, Shiraz, Iran
Correspondence: Behrooz Astaneh

Vice-Chancellor for Research

Department, Shiraz University of Medical

Sciences, Zand Street,

Shiraz, Iran

Tel +98 917 III I I I

Email astanehb@yahoo.com

\begin{abstract}
Familial hypercholesterolemia is an autosomally dominant disorder caused by various mutations in low-density lipoprotein receptor genes. This will lead to elevated levels of total and low-density lipoprotein cholesterol, which may in turn lead to premature coronary atherosclerosis and cardiac-related death. The symptoms are more severe in the homozygous type of the disease. Different options for the treatment of affected patients are now available. Diet therapy, pharmacologic therapy, lipid apheresis, and liver transplantation are among the various treatments. We clinically review the treatment and management strategies for the disease in order to shed light on the optimal management of familial hypercholesterolemia.
\end{abstract}

Keywords: familial hypercholesterolemia, homozygote, heterozygote, Iran

\section{Introduction}

Familial hypercholesterolemia is a genetic autosomal dominant disorder caused by various mutations in low-density lipoprotein (LDL) receptor gene, which is located on chromosome 19. The more than 700 mutations can cause defects in LDL receptors which are located mainly in the liver. ${ }^{1,2}$ The main function of LDL receptors is removing the LDL particles from the plasma by endocytosis. ${ }^{1}$ Various degrees of such defects can cause different symptom severities. The most severe form is related to total lack of receptors (receptor-negative mutations), while 'receptor-defective' mutations that comprise most of the mutations are usually accompanied by lesser symptoms. ${ }^{1}$ The mutations differ in various populations leading to a variety of symptoms and severity in different countries. ${ }^{3-6}$

These mutations lead to the specific phenotype of familial hypercholesterolemia. There are two other genes whose mutations can cause a similar phenotype; the gene related to apolipoprotein B-100 and the newly recognized proprotein convertase subtilisin/kexin type 9.

The consequences of such defects in LDL receptor genes are changes in vascular endothelial function, ${ }^{7}$ high total serum cholesterol (usually more than $290 \mathrm{mg} / \mathrm{dL}$; $7.5 \mathrm{mmol} / \mathrm{L}$ ), and high serum LDL (usually above $190 \mathrm{mg} / \mathrm{dL} ; 4.9 \mathrm{mmol} / \mathrm{L}$ ). The values in children may vary, but hypercholesterolemia usually lead to atherosclerotic changes in coronary arteries, as well as formation of tendon xanthomas. ${ }^{1}$ Familial hypercholesterolemia is also associated with increased peripheral arterial diseases, as well as increased thickness of intima media of femoral and carotid arteries, although reviews have shown that more evidence is needed to link a conclusive association between this disease and risk of stroke. ${ }^{8}$ Tendon xanthomas that are caused by 
deposition of high cholesterol in tendons and skin are seen in elbows, knees, Achilles tendon, hands, and other parts of the body (Figures 1 and 2). Tendon xanthoma is highly suggestive of familial hypercholesterolemia and is a basic criterion in the clinical diagnosis of this disease. In some studies, about one-third of patients with familial hypercholesterolemia had displayed xanthomas, although up to $50 \%$ of such patients can be affected. ${ }^{9}$ It has been shown that tendon xanthomas are associated with increased risk of cardiovascular disease independent of gene mutation. Moreover, the risk in women is much higher than men. This warrants the need for caution and start to lipid-lowering management as early as possible in when such xanthomas are defected. ${ }^{9}$ Excessive cholesterol can also deposit in the cornea, causing corneal arcus (Figure 3).

There are two types of familial hypercholesterolemia; heterozygous and homozygous. The mode of inheritance of the heterozygous type is autosomal dominant. The incidence of the former type is about 1 in 500, and signs of hypercholesterolemia, including coronary heart disease and xanthomas, are usually presented in patients older than 20 years. ${ }^{2}$ The homozygous type of the disease, which is an autosomal codominant disorder, has an incidence of one in a million and is usually presented in earlier years of life accompanied by more severe signs and symptoms leading to coronary artery bypass grafting $(\mathrm{CABG})$ in the second decade of life. ${ }^{10-12}$

Involvement of the cardiac valve is another important and serious complication in the natural course of the disease. ${ }^{13}$ The aortic valve is usually involved, and this can be independent of the atherosclerotic changes in the coronary arteries as the involvement of the aortic valve in the presence of intact grafted coronary vessels has been reported. ${ }^{14}$

\section{Treatment options}

Various treatment options have been proposed to manage familial hypercholesterolemia. ${ }^{15,16}$ Each has some advantages

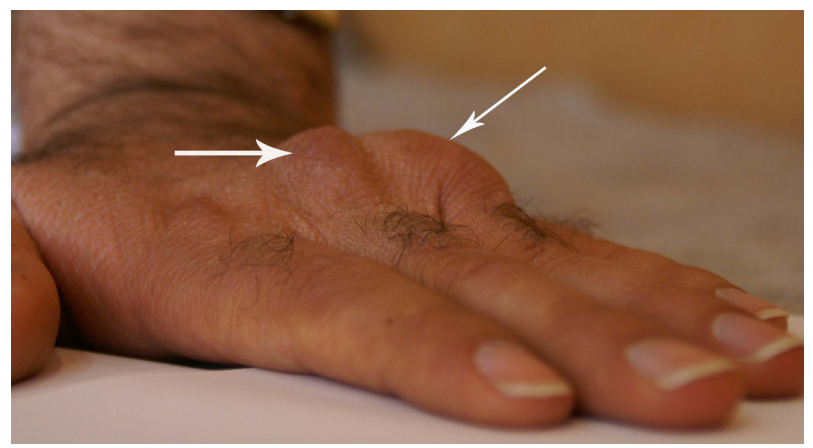

Figure I Xanthoma in volar surface of left hand in a patient with homozygous familial hypercholesterolemia.

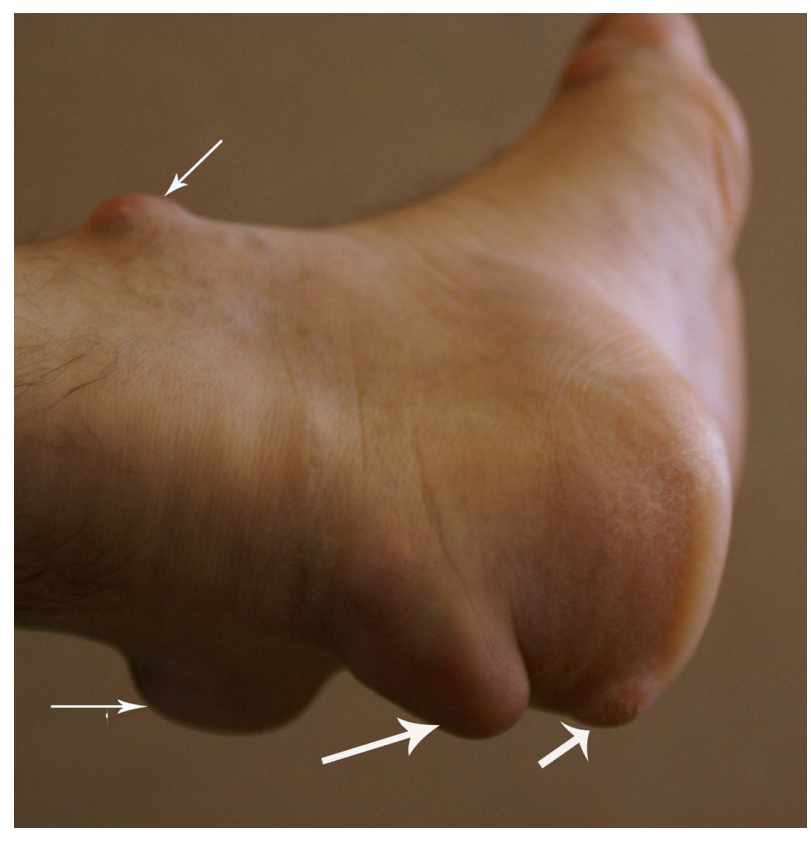

Figure 2 Xanthoma of Achilles tendon in a patient with homozygous familial hypercholesterolemia.

and disadvantages (Table 1). The options include changes in lifestyle and diet regulation, pharmacologic therapy with different categories of drugs affecting various pathways of cholesterol absorption and metabolism and invasive procedures including lifelong lipid apheresis, and finally, liver transplantation.

\section{Dietary treatment}

There is a recommendation from the American Heart Association that, dietary treatment should be added to other pharmacological treatments in children and adolescents. ${ }^{17}$

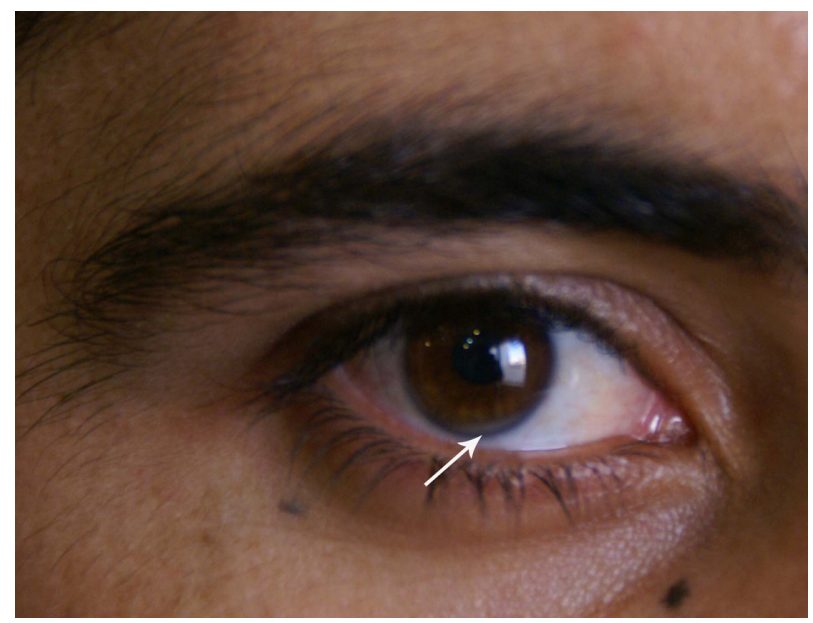

Figure 3 Corneal arcus eye in a patient with homozygous familial hypercholesterolemia. 
Table I Comparison of various treatment modalities in familial hypercholesterolemia

\begin{tabular}{|c|c|c|c|}
\hline & Characteristics & Advantages & Disadvantages \\
\hline Diet & $\begin{array}{l}\text { Reduced fat, saturated fatty acids, and } \\
\text { cholesterol intake. Consider carbohydrates } \\
\text { to compensate the low energy caused by } \\
\text { low-fat diet }\end{array}$ & $\begin{array}{l}\text { Need to lower doses } \\
\text { of pharmacologic drugs }\end{array}$ & $\begin{array}{l}\text { Lower intake of fat-soluble vitamins, } \\
\text { lower levels of HDL, and increase in } \\
\text { triglycerides }\end{array}$ \\
\hline Drugs & $\begin{array}{l}\text { Can decrease LDL and triglycerides, } \\
\text { or increase HDL }\end{array}$ & $\begin{array}{l}\text { Effective blood cholesterol } \\
\text { control }\end{array}$ & Drug-specific side effects \\
\hline Lipid apheresis & $\begin{array}{l}\text { For homozygous patients or heterozygous } \\
\text { nonresponsive to drug therapy }\end{array}$ & $\begin{array}{l}\text { Rapid LDL decrease to } 40 \%-60 \% \\
\text { retards the progression of } \\
\text { intima-media thickness }\end{array}$ & $\begin{array}{l}\text { Invasiveness, rebound LDL } \\
\text { increase, no availability in all } \\
\text { centers }\end{array}$ \\
\hline Liver transplantation & $\begin{array}{l}\text { Treatment of choice for patients who } \\
\text { are not responsive to routine } \\
\text { pharmacologic treatments }\end{array}$ & $\begin{array}{l}\text { Transfer a rich source of } \\
\text { functioning LDL receptors, } \\
\text { resolution of the symptoms }\end{array}$ & $\begin{array}{l}\text { Long-term immunosuppression, lack } \\
\text { of facility in most centers, restricted } \\
\text { donors }\end{array}$ \\
\hline
\end{tabular}

Abbreviations: HDL, high-density lipoprotein; LDL, low-density lipoprotein.

Dietary interventions in some countries aim to reduce fat, saturated fatty acids, and cholesterol intake and to consider carbohydrates to compensate for the low energy caused by low-fat diet. ${ }^{2}$ For patients with risk factors, saturated fatty acids are restricted to a maximum of $7 \%$ of total calorie intake and dietary cholesterol to $200 \mathrm{mg} /$ day. ${ }^{18}$ Along with the positive effects of the diet, some problems including lower intake of fatsoluble vitamins and lower levels of HDL as well as an increase in triglycerides caused by high carbohydrate intake may occur. Recommendations include using normal total fat intake and increasing some dietary components including omega- 3 fatty acids and soy protein. ${ }^{17}$ However, a recent review on the effectiveness of such dietary intervention reported no definite conclusion because of the lack of adequate data. ${ }^{2}$

For children with $\mathrm{LDL}>190 \mathrm{mg} / \mathrm{dL}(4.9 \mathrm{mmol} / \mathrm{L})$, it is unlikely that dietary treatment alone can lower the cholesterol level to an acceptable concentration; however, dietary intervention should be a major part of any long-term treatment because it can lead to a lower dose of pharmacologic drugs. ${ }^{18}$

\section{Pharmacologic treatments}

There is strong evidence that atherosclerotic changes begin in childhood and the severity of lipid abnormalities leads to increase in such changes. The first evidence came from the autopsies done on soldiers killed during wars, including the Vietnam War. A survey on those autopsies showed that about half of the young soldiers with a mean age of 22 years had evidence of coronary atherosclerosis and some were severely affected. ${ }^{19}$ It would be rational to start aggressive treatment in early ages to reach the treatment goal of $<130 \mathrm{mg} / \mathrm{dL}$ $(3.4 \mathrm{mmol} / \mathrm{L})$ or $<110 \mathrm{mg} / \mathrm{dL}(2.8 \mathrm{mmol} / \mathrm{L})$ in those with other risk factors. ${ }^{17,18}$ The epidemic of obesity in children in most developed countries makes the treatment necessary. Besides, as the lifestyle changes are not sufficiently effective, ${ }^{17}$ it is recommended that in children older than 10 years, along with a dietary intervention, some sort of drug should be started to control the high blood cholesterol level in those having LDL $>160 \mathrm{mg} / \mathrm{dL}(4.1 \mathrm{mmol} / \mathrm{L})$ with family history of coronary artery disease or LDL $>190 \mathrm{mg} / \mathrm{dL}$ ( $4.9 \mathrm{mmol} / \mathrm{L}$ ) without such history. ${ }^{20} \mathrm{~A}$ recent recommendation by the National Cholesterol Education Program notes that even in adult patients with $0-1$ risk factors and LDL cholesterol level of 160-189 mg/dL, drug therapy can be considered after a trial of lifestyle change. For those patients with $\mathrm{LDL} \geq 190 \mathrm{mg} / \mathrm{dL}$, drug therapy is recommended. ${ }^{21}$

Various drugs have been proposed for such purposes. All have advantages and disadvantages.

\section{Bile acid sequestrants}

Use of bile acid sequestrants such as cholestyramine showed that they only have minor effects on lowering cholesterol levels. ${ }^{22}$ Besides, their tolerability was a major concern. Liacouras et al reported that most of the children they treated with cholestyramine discontinued the drug after about 22 months of treatment because of gastrointestinal side effects. ${ }^{23}$

Fenofibrate from the fibrate class is another drug with the license for use in children. ${ }^{2}$ It works by activating the peroxisome proliferator-activated receptor type alpha. Fenofibrate was assumed to be able to lower LDL. However, Tonstad reported that there was little evidence for its effectiveness in children, although it was well tolercated. ${ }^{24}$

\section{Statin therapy}

The other category of drugs that have been used effectively in adults with hypercholesterolemia are hydroxymethylglutaryl coenzyme A (HMG-CoA) reductase inhibitors. ${ }^{25-27}$ Statins have also shown favorable results and safety profile in 
adolescents, although response to these drugs is reported to be dependent on LDL receptor genotype. ${ }^{28,29}$ It was reported that the response to statins in decreasing the LDL and apolipoprotein B was affected by the class of mutation. Patients with class $\mathrm{V}$ mutations, in whom the internalized LDL particles cannot be released into the endosomes ${ }^{1}$, show a higher decrease in LDL and apolipoprotein B levels after treatment with statins. ${ }^{30}$ This finding was contrary to the results of Sun et al who reported that patients with severe mutations had higher LDL cholesterol during treatment with simvastatin, ${ }^{31}$ while Sijbrands et al reported similar lipidlowering response in heterozygous patients with either mRNApositive or mRNA-negative LDL receptor mutations. ${ }^{32}$

A prominent effect of statins is that they can improve endothelial dysfunction caused by hypercholesterolemia. ${ }^{33}$ Along with their benefits, some side effects including myopathy have been reported. ${ }^{34-36}$ For new users, a threefold increase in the risk of myopathy has been reported for women, while such risk for men is about sixfold. In addition, the risk is different in various ethnicities. ${ }^{35}$ The drugs are also contraindicated in pregnancy because of the possible side effects on the fetus.

\section{Statin therapy: lovastatin}

Lovastatin is an effective inhibitor of HMG-CoA reductase, which catalyzes the conversion of hydroxymethylglutarate to mevalonate. This is a rate-limiting step in the process of cholesterol synthesis. ${ }^{37}$ The effect of lovastatin to decrease serum total or LDL cholesterol was reported to be similar in patients with different gene mutations. Vuorio et al reported that lovastatin efficacy was similar in patients with Helsinki gene compared with patients having North Karelia gene. ${ }^{38}$

In a double-blind, randomized, placebo-controlled study, Clauss et al compared the efficacy of diet plus two different doses of lovastatin (20 and $40 \mathrm{mg} /$ day) with diet plus placebo in a group of adolescent girls with heterozygous familial hypercholesterolemia. ${ }^{37}$ They reported that lovastatin at doses up to $40 \mathrm{mg} /$ day could reduce LDL and total cholesterol. They also reported good tolerability of lovastatin in their group of adolescent girls with hypercholesterolemia. ${ }^{37}$

\section{Statin therapy: pravastatin}

The efficacy and safety of statins have been reported in some other studies. ${ }^{39-41}$ The US Food and Drug Administration has approved prescribing pravastatin for treatment of heterozygous familial hypercholesterolemia in children older than 8 years. ${ }^{42}$ Wiegman et al reported a 2 -year study of such parameters in children and adolescents with heterozygous familial hypercholesterolemia treated with pravastatin. ${ }^{28}$ Although there was a concern about the long-term effects of statins in the growth and sexual development of children treated with such drugs, they reported no adverse effects on these aspects as well as on hormone levels or muscular or liver tissues. They assessed the safety by measuring the carotid intima-media thickness before and after the treatment, which showed a trend toward regression after treatment with pravastatin compared with the placebo group. Similar results regarding the safety and tolerability of pravastatin was reported by Hedman et al, although they reported that the efficacy was insufficient in children with severe hypercholesterolemia. ${ }^{42}$

\section{Statin therapy: rosuvastatin}

Rosuvastatin, another $\mathrm{HMG}-\mathrm{CoA}$ reductase inhibitor, has been prescribed in adults with hypercholesterolemia with favorable effects. ${ }^{43}$ Its effects in children were assessed also in a large, multicenter, double-blind, placebo-controlled study. ${ }^{44}$ The researchers compared the various doses of rosuvastatin (5-20 mg/day) with placebo in a group of pubertal patients (10-17 years old) with heterozygous familial hypercholesterolemia in 20 centers around Europe and North America. A maximum of $20 \mathrm{mg}$ rosuvastatin daily could reduce LDL by $50 \%$; however, only $40 \%$ of the patients could achieve the LDL serum level $<110 \mathrm{mg} / \mathrm{dL}(2.8 \mathrm{mmol} / \mathrm{L})$ recommended for children with hypercholesterolemia accompanied by other risk factors. ${ }^{18,44}$ This study showed that statin therapy in children could be safe.

\section{Statin therapy: simvastatin}

Simvastatin is another member of this drug family. Its effect on patients with the heterozygous disease type who had different types of mutations in LDL receptor genes was assessed by Heath et al. ${ }^{45}$ In accordance with Sun et $\mathrm{al}^{31}$ they reported that, of their patients with severe mutations, fewer achieved optimal LDL cholesterol compared with their control group of patients with mild mutations. They found that this difference was statistically significant at $40 \mathrm{mg} /$ day of simvastatin. ${ }^{45}$

\section{Statin therapy: meta-analyses}

Meta-analyses of articles that studied statins in the treatment of familial hypercholesterolemia reported the same results. Arambepola et al analyzed 18 articles, which were matched with their search criteria; ${ }^{46} 11$ were trials, including 8 randomized controlled trials, and the remaining 7 were case series. Their meta-analysis showed an overall $32 \%$ reduction in LDL 
cholesterol and $1.9 \mathrm{mmol} / \mathrm{L}$ absolute reduction in LDL after treatment with various types of statins including lovastatin, pravastatin, simvastatin, and atorvastatin in children aged 8-18 years with heterozygous familial hypercholesterolemia. Statins could also increase HDL by $3.4 \%$ but had no significant effect on reduction of triglycerides. ${ }^{46}$ Based on such findings, they finally concluded that statin monotherapy is safe, well tolerated, and efficacious. However, long-term safety was still a concern.

Another systematic review of statin therapy in children with heterozygous familial hypercholesterolemia was reported by Avis et al who analyzed six randomized, double-blind, placebo-controlled trials evaluating various types of statins. ${ }^{27}$ The statins included atorvastatin, pravastatin, simvastatin, and lovastatin. They reported that treatment with statins led to significant reduction in total cholesterol, LDL, and apolipoprotein B. HDL was increased after treatment, but there was no significant difference between the treated groups and the placebo groups in adverse effects such as muscle toxicity, sexual development, and liver toxicity. They suggested using statin treatment for children with heterozygous familial hypercholesterolemia, although they recommended that further assessment of lifelong safety was needed. ${ }^{27}$

In the homozygous type, a main cause of mortality and morbidity is aortic stenosis rather than involvement of the coronary arteries. A direct relation between aortic stenosis and hypercholesterolemia has been reported. ${ }^{47}$ It was also shown that aortic stenosis can be developed many years after bypass graft and even with antilipid treatment. ${ }^{14}$

\section{Statins combined with other drugs}

Some other medications have been proposed to add to statins to enhance their effectiveness. ${ }^{48,49}$ Ezetimibe, a selective inhibitor of cholesterol absorption, binds to a protein called Niemann-Pick C1 like 1, which is located at the brush border membrane of enterocytes, and contributes to intestinal uptake of cholesterol..$^{50}$ The effects of combined treatment of statins and ezetimibe have been reported to reduce LDL up to $20 \%$ in some studies. ${ }^{49,51}$ In a randomized, double-blind, multicenter trial on adults with hypercholesterolemia, Kastelein et al compared the effects of treatment with simvastatin with either placebo or 10-mg ezetimibe in a group of patients during a 2-year period..$^{50}$ They measured the intima-media thickness of carotid and femoral arteries as well as the changes in the blood levels of LDL, triglycerides, and C-reactive protein. Although they reported no difference between the intimamedia thickness of carotid and femoral arteries between the two groups, they found significant reduction in LDL, triglycerides, and C-reactive protein after combined treatment with ezetimibe. ${ }^{50}$ More effectiveness can be achieved by adding other drugs such as niacin as it has been reported that combined treatment with simvastatin/ezetimibe and niacin had had superior effects in reduction of LDL compared with simvastatin/ezetimibe or niacin-alone treatment in patients with hyperlipidemia. ${ }^{52}$

\section{Pharmacotherapeutic need for newer drugs}

Still there are concerns that the optimal goals for treatment of hypercholesterolemia might be hard to achieve. As reported by Avis et al, only $40 \%$ of their patients achieved the treatment goal. ${ }^{44}$ Reports from other countries highlight the same concern. Pijlman et al reported that only $21 \%$ of the patients with heterozygous hypercholesterolemia in the Netherlands achieved the treatment goal, which required new medical options to be combined with current treatments. ${ }^{53}$ Mipomersen, a second-generation antisense oligonucleotide, can inhibit the synthesis of apolipoprotein B-100, which is an essential component of all atherogenic lipoproteins such as LDL and has been used to lower cholesterol level in patients with hypercholesterolemia. ${ }^{54}$ In a multicenter, randomized, double-blind, placebo-controlled trial, Raal et al used mipomersen to treat patients with homozygous familial hypercholesterolemia older than 12 years who were already receiving maximum tolerated doses of lipid-lowering drugs. ${ }^{55}$ They injected $200 \mathrm{mg}$ mipomersen subcutaneously every week for 26 weeks to a treatment group and compared them with those who received placebo. Mipomersen reduced LDL levels by a mean of $25 \%$ and by an absolute reduction of more than $2.5 \mathrm{mmol} / \mathrm{L}$. It could also increase the HDL concentration by about $15 \%$. Although there were some side effects including mild erythema of the injection site and influenza like symptoms, they introduced mipomersen as a novel and effective treatment to be added to other drugs for refractory hypercholesterolemia. ${ }^{55}$

\section{Lipid apheresis}

Lipid apheresis is an accepted method for treating patients with heterozygous familial hypercholesterolemia who are unresponsive to pharmacologic therapy or for those with the homozygous disease type. It is now considered the treatment of choice for the latter group of patients. ${ }^{56}$ It is advised to combine apheresis with maximum-tolerated doses of statins plus ezetimibe. ${ }^{48}$ As the LDL receptors in patients with homozygous familial hypercholesterolemia are mostly 
not functional, such patients usually do not respond well to routine antilipid treatments such as statins whose main function is upregulating LDL receptors in the liver. ${ }^{55}$

There are various methods for lipid apheresis; $;{ }^{57}$ it is usually performed to lower the LDL level by $40 \%-60 \%{ }^{58}$ But there will be a rebound in the LDL level after each session. The nature of the cholesterol rebound differs in different individuals. It is very fast in normal individuals, slower in patients with heterozygous hypercholesterolemia, and slowest in patients with the homozygous disease type. ${ }^{59}$ After 2 weeks, patients with heterozygous types will return to the baseline level, while this period for homozygous patients is about 3-4 weeks. That is why fortnightly sessions of apheresis in homozygous patients lead to a reduction of cholesterol in a larges percentage compared with the heterozygous patients. Regular sessions of apheresis lead to lower levels of cholesterol after rebounds. ${ }^{59}$ LDL apheresis can also retard the progression of intima-media thickness. ${ }^{60}$

For effective apheresis, two good veins are required; For patients with poor venous access, an atriovenous fistula should be performed. ${ }^{61}$ Long-term effects of lipid apheresis in homozygous patients have been reported, although there are concerns about the expenses and the invasiveness of the procedure. ${ }^{55,61}$ In addition, it is not a procedure that is available in all centers. ${ }^{10,12}$

Thompson and colleagues recommend that the target level for homozygous patients who receive lipid apheresis should be an acute reduction in LDL $>70 \%$ or in total cholesterol $>65 \%$ after each session. They also suggest a baseline of total cholesterol $<9 \mathrm{mmol} / \mathrm{L}$ or $\mathrm{LDL}$ $<8.5 \mathrm{mmol} / \mathrm{L}^{59}$

\section{Liver transplantation}

Operative strategies to reduce blood cholesterol have been proposed previously. However, as it is known that most of the LDL receptors are located in the liver, this procedure has become a treatment of choice for affected patients non responsive to routine pharmacologic treatments. ${ }^{10,12,62,63}$ Although there is always a concern about long-term immunosuppression, the lack of facilities in most centers, as well as restricted donors, ${ }^{55}$ and improvements in surgical techniques and immunologic approaches, have led to favorable outcomes after transplantation. ${ }^{64}$

The transplanted liver retains the specific qualities of the donor, so liver transplantation can transfer a rich source of functioning LDL receptors to the recipient, which may lead to a cure of the hypercholesterolemia and resolution of the symptoms. However, the success of this type of treatment depends on the total functional receptors transplanted; hence, to the graft size. ${ }^{64}$ That is why auxiliary liver grafts cannot be used for such patients. Having considered that there are other sources of LDL receptors in the body rather than the liver, complementary treatments after transplantation may be needed in some severely affected patients. ${ }^{65}$

Hypercholesterolemia, if untreated, finally will lead to severe cardiac disease. Successful combined heart and liver transplantation has been reported earlier. ${ }^{66,67}$ However, it is currently, recommended that liver transplantation should be done before end-stage cardiac disease necessitates a heart transplant. ${ }^{64}$

\section{Surgical management of affected heart and vascular system}

Hypercholesterolemia can affect heart and vascular system by deposition of cholesterol in coronary arteries, heart valves, and carotid arteries. In the homozygous type, the symptoms present in early years of life. ${ }^{10-12,14}$

\section{Cardiac involvement}

In many cases, such patients present first with cardiac symptoms, and through screening, their hyperlipidemia may be discovered. It is recommended that any child with positive family history and risk factors who presented with chest pain should be extensively evaluated. Exercise tolerance test is positive in such patients, and coronary angiography should be done to demonstrate the extent of coronary involvement, which is usually in an advanced stage. The left main coronary artery is usually affected, and CABG is the preferred treatment option instead of percutaneous coronary intervention. After considering the lower ages of patients with homozygous hypercholesterolemia, the choice of conduits for grafting is arterial; however, favorable results have been reported from venous grafts. ${ }^{11,12}$

If a compromised heart might endanger patients during a major operative procedure such as liver transplantation, cardiac surgery before transplantation is recommended. ${ }^{68}$ We recommend performing CABG before liver transplantation because of the advanced stage of coronary artery disease and involvement of left main coronary artery compromise the heart.

\section{Carotid involvement}

Other than coronary arteries, carotid arteries are most prone to obstruction caused by cholesterol deposition; however, because of the larger caliber than the coronary arteries, carotids may be affected in the later decades of life. We have previously 
operated on a 14-year-old patient with homozygous type. ${ }^{14}$ During the long-term follow-up of the patient, we found that both his carotids were obstructed at the age of 24 years (10 years after the CABG). Treatment of such obstructions in the carotid can be performed by stenting.

\section{Aortic involvement}

Ascending aorta and the valve are two other common structures of the heart that can be affected. Atherosclerotic changes in the wall of the ascending aorta lead to supravalvular stenosis, and deposition of cholesterol on the aortic valve may lead to aortic stenosis. Such aortic valve involvement can be present even without coronary involvement. In our previously reported case, the patient's aortic valve was affected after 5 years of $\mathrm{CABG}$ while neither his grafted vessels nor the native ones were affected during that period. ${ }^{14}$ Management of aortic involvement can be pharmacologic or surgical, depending on the severity of the disease. Favorable effects of using statins to slow the progression of aortic stenosis have been reported, ${ }^{69}$ although their efficacy has been attributed to some degree to their anti-inflammatory effects. ${ }^{70}$ In case 5 of severe aortic stenosis, aortic valve replacement, which is accompanied by favorable outcome, is recommended in such patients. ${ }^{14}$

After the $\mathrm{CABG}$ or aortic replacement, in patients with homozygous type for whom the pharmacologic treatment is not effective, liver transplantation must be performed as soon as possible to prevent the recurrence of hypercholesterolemic changes in the grafted vessels or the replaced aorta.

\section{Screening}

As familial hypercholesterolemia is an autosomal dominant genetic disorder with full penetrance, it is logical that a patient with the disease will have some other affected relatives in his/her family. ${ }^{71}$ Bhatnagar et al reported that they found 121 new patients by screening and cholesterol testing 200 relatives of patients with heterozygous familial hypercholesterolemia. ${ }^{72}$ Having considered the 1/500 frequency of the heterozygous type in European countries, this ratio of patients could be detected in a population-based study by performing as large as 60,000 tests. Guidelines of screening for familial hypercholesterolemia still follow the rules released by the expert panel in 1992. ${ }^{17,20}$ The panel recommended two approaches: a population-based approach to modify the fat intake and a targeted screening approach to find people with high LDL who need further management. However, there was a concern about universal screening because it was believed that this approach might label some children as having a 'disease', hence, selective screening was recommended for those children and adolescents with family history of a parent aged $<55$ years who had coronary, peripheral, or cerebral vascular atherosclerosis or a parent with sudden cardiac death, myocardial infarction, or previous coronary artery operations. ${ }^{17}$ For the children screened, their lipid profile should be checked twice and lifestyle and dietary changes should be started when LDL levels are high. Drug therapy should be started for children with persistent elevated LDL ( $>190 \mathrm{mg} / \mathrm{dL})$ who are not responsive to diet therapy or for children with LDL $>160 \mathrm{mg} / \mathrm{dL}$ ( $4.1 \mathrm{mmol} / \mathrm{L})$ accompanied by at least two other risk factors. ${ }^{17}$ Children with diabetes mellitus should receive drugs if their LDL blood level exceeds $130 \mathrm{mg} / \mathrm{dL}$ $(3.4 \mathrm{mmol} / \mathrm{L}){ }^{18}$

It is also recommended to focus on the pregnancy period of women with hypercholesterolemia. The lipid profile of the partner should be checked, and if he is found to be hypercholesterolemic, utero-genetic evaluation should be performed to find out if the fetus has the homozygous type. ${ }^{61}$

\section{The future}

Considering the serious side effects of hypercholesterolemia and its considerable rate of mortality and morbidity, novel methods for treating the disease are steadily sought by researchers. Gene therapy may be a remedy for this disease. ${ }^{73}$ Raper et al reported that liver-directed ex vivo gene therapy can be done safely in selected patients. ${ }^{74}$ Others used different methods, including adenovirus gene transfer, to study the function of lipoprotein receptors. ${ }^{75}$ Human amniotic epithelial cells as a transgene carrier has been reported as a favorable approach for gene therapy in patients with familial hypercholesterolemia. ${ }^{76} \mathrm{New}$ improvements in methods of gene therapy have increased the hope of reaching an optimal management of familial hypercholesterolemia in future. ${ }^{77}$

\section{Conclusion}

Familial hypercholesterolemia is a serious genetic disorder affecting patients in the early years of life. Early diagnosis and optimal management is crucial to prevent the high rate of mortality and morbidity caused by the disease. Various treatment options are available at the moment. Diet and pharmacologic therapies are the first steps. Statins have shown favorable effects in various trails. They are effective both in adults and children. Invasive procedures such as LDL apheresis are reserved for homozygous-type patients or for heterozygous patients who are not responsive to routine drug therapy. Liver 
transplantation is the last resort for treating such patients. It has the capability to replenish the body with functional LDL receptors, which may lead to a cure of the disease.

\section{Disclosure}

The authors report no conflicts of interest in this work.

\section{References}

1. Austin MA, Hutter CM, Zimmern RL, Humphries SE. Familial hypercholesterolemia and coronary heart disease: a HuGE association review. Am J Epidemiol. 2004;160(5):421-429.

2. Shafiq N, Singh M, Kaur S, Khosla P, Malhotra S. Dietary treatment for familial hypercholesterolaemia. Cochrane Database Syst Rev. 2010 Jan 20;(1):CD001918.

3. Bertolini S, Cassanelli S, Garuti R, et al. Analysis of LDL receptor gene mutations in Italian patients with homozygous familial hypercholesterolemia. Arterioscler Thromb Vasc Biol. 1999;19(2): 408-418.

4. Bujo H, Takahashi K, Saito Y, et al. Clinical features of familial hypercholesterolemia in Japan in a database from 1996-1998 by the research committee of the ministry of health, labour and welfare of Japan. J Atheroscler Thromb. 2004;11(3):146-151.

5. Cao S, Wang L, Qin Y, et al. Analysis of low-density lipoprotein receptor gene mutations in a Chinese patient with clinically homozygous familial hypercholesterolemia. Chin Med J (Engl). 2003;116(10): $1535-1538$.

6. Chiou KR, Charng MJ. Detection of mutations and large rearrangements of the low-density lipoprotein receptor gene in Taiwanese patients with familial hypercholesterolemia. Am J Cardiol. 2010;105(12): $1752-1758$.

7. Aggoun Y, Bonnet D, Sidi D, et al. Arterial mechanical changes in children with familial hypercholesterolemia. Arterioscler Thromb Vasc Biol. 2000;20(9):2070-2075.

8. Hutter CM, Austin MA, Humphries SE. Familial hypercholesterolemia, peripheral arterial disease, and stroke: a HuGE minireview. Am J Epidemiol. 2004;160(5):430-435.

9. Civeira F, Castillo S, Alonso R, et al. Tendon xanthomas in familial hypercholesterolemia are associated with cardiovascular risk independently of the low-density lipoprotein receptor gene mutation. Arterioscler Thromb Vasc Biol. 2005;25(9):1960-1965.

10. Nemati MH. Coronary revascularization in a child with homozygous familial hypercholesterolemia. Interact Cardiovasc Thorac Surg. 2010;10(1):131-132.

11. Nemati MH, Astaneh B. Coronary artery bypass grafting in a 12 year old with familial hypercholesterolemia. Acta Chir Belg. 2009;109(4): $570-571$.

12. Nemati MH, Astaneh B, Joubeh A. Triple coronary artery bypass graft in a 10-year-old child with familial hypercholesterolemia. Gen Thorac Cardiovasc Surg. 2009;57(2):94-97.

13. Harikrishnan S, Byju CK, Tharakan J. Severe valvar aortic stenosis in a child with familial hypercholesterolaemia. Heart. 2004;90(3):238.

14. Nemati MH. Aortic stenosis five years after coronary artery bypass grafting in a young patient with homozygous familial hypercholesterolemia. J Heart Valve Dis. 2009;18(1):125-127.

15. Huijgen R, Vissers MN, Defesche JC, Lansberg PJ, Kastelein JJ, Hutten BA. Familial hypercholesterolemia: current treatment and advances in management. Expert Rev Cardiovasc Ther. 2008;6(4): $567-581$.

16. Iughetti L, Predieri B, Balli F, Calandra S. Rational approach to the treatment for heterozygous familial hypercholesterolemia in childhood and adolescence: a review. J Endocrinol Invest. 2007;30(8):700-719.
17. McCrindle BW, Urbina EM, Dennison BA, et al. Drug therapy of high-risk lipid abnormalities in children and adolescents: a scientific statement from the American Heart Association Atherosclerosis, Hypertension, and Obesity in Youth Committee, Council of Cardiovascular Disease in the Young, with the Council on Cardiovascular Nursing. Circulation. 2007;115(14):1948-1967.

18. Daniels SR, Greer FR. Committee on Nutrition. Lipid screening and cardiovascular health in childhood. Pediatrics. 2008;122(1):198-208.

19. McNamara JJ, Molot MA, Stremple JF, Cutting RT. Coronary artery disease in combat casualties in Vietnam. JAMA. 1971;216(7): 1185-1187.

20. National Cholesterol Education Program (NCEP): highlights of the report of the expert panel on blood cholesterol levels in children and adolescents. Pediatrics. 1992;89(3):495-501.

21. Third report of the National Cholesterol Education Program (NCEP) expert panel on detection, evaluation, and treatment of high blood cholesterol in adults (Adult Treatment Panel III) final report. Circulation. 2002;106(25):3143-3421.

22. Tonstad S, Knudtzon J, Sivertsen M, Refsum H, Ose L. Efficacy and safety of cholestyramine therapy in peripubertal and prepubertal children with familial hypercholesterolemia. J Pediatr. 1996;129(1):42-49.

23. Liacouras CA, Coates PM, Gallagher PR, Cortner JA. Use of cholestyramine in the treatment of children with familial combined hyperlipidemia. J Pediatr. 1993;122(3):477-482.

24. Tonstad S. A rational approach to treating hypercholesterolaemia in children. Weighing the risks and benefits. Drug Saf. 1997;16(5):330-341.

25. Alonso R, Mata N, Mata P. Benefits and risks assessment of simvastatin in familial hypercholesterolaemia. Expert Opin Drug Saf. 2005;4(2): $171-181$.

26. Avellone G, Di Garbo V, Abruzzese G, et al. One-year atorvastatin treatment in hypercholesterolemic patients with or without carotid artery disease. Int Angiol. 2006;25(1):26-34.

27. Avis HJ, Vissers MN, Stein EA, et al. A systematic review and metaanalysis of statin therapy in children with familial hypercholesterolemia. Arterioscler Thromb Vasc Biol. 2007;27(8):1803-1810.

28. Wiegman A, Hutten BA, de Groot E, et al. Efficacy and safety of statin therapy in children with familial hypercholesterolemia: a randomized controlled trial. JAMA. 2004;292(3):331-337.

29. Choumerianou DM, Dedoussis GV. Familial hypercholesterolemia and response to statin therapy according to LDLR genetic background. Clin Chem Lab Med. 2005;43(8):793-801.

30. Miltiadous G, Xenophontos S, Bairaktari E, Ganotakis M, Cariolou M, Elisaf M. Genetic and environmental factors affecting the response to statin therapy in patients with molecularly defined familial hypercholesterolaemia. Pharmacogenet Genomics. 2005;15(4):219-225.

31. Sun XM, Patel DD, Knight BL, Soutar AK. Influence of genotype at the low density lipoprotein (LDL) receptor gene locus on the clinical phenotype and response to lipid-lowering drug therapy in heterozygous familial hypercholesterolaemia. The Familial Hypercholesterolaemia Regression Study Group. Atherosclerosis. 1998;136(1):175-185.

32. Sijbrands EJ, Lombardi MP, Westendorp RG, et al. Similar response to simvastatin in patients heterozygous for familial hypercholesterolemia with mRNA negative and mRNA positive mutations. Atherosclerosis. 1998;136(2):247-254.

33. Brown SL, Raal FJ, Panz VR, Stevens BA, Veller MG. High-dose atorvastatin therapy is required for significant improvement of endothelial function in heterozygous familial hypercholesterolaemic patients. Cardiovasc J S Afr. 2004;15(2):70-75.

34. Fadini GP, Manzato E, Crepaldi C, de Kreutzenberg S, Tiengo A, Avogaro A. Two cases of statin-induced rhabdomyolysis associated with mononeuropathy. Clin Drug Investig. 2010;30(5):347-350.

35. Hippisley-Cox J, Coupland C. Individualising the risks of statins in men and women in England and Wales: population-based cohort study. Heart. 2010;96(12):939-947.

36. Hyman MH. Issues in statin-associated myopathy. JAMA. 2003; 290(7):888-889. 
37. Clauss SB, Holmes KW, Hopkins P, et al. Efficacy and safety of lovastatin therapy in adolescent girls with heterozygous familial hypercholesterolemia. Pediatrics. 2005;116(3):682-688.

38. Vuorio AF, Ojala JP, Sarna S, Turtola H, Tikkanen MJ, Kontula K. Heterozygous familial hypercholesterolaemia: the influence of the mutation type of the low-density-lipoprotein receptor gene and PvuII polymorphism of the normal allele on serum lipid levels and response to lovastatin treatment. J Intern Med. 1995;237(1):43-48.

39. Knipscheer HC, Boelen CC, Kastelein JJ, et al. Short-term efficacy and safety of pravastatin in 72 children with familial hypercholesterolemia. Pediatr Res. 1996;39(5):867-871.

40. Lambert M, Lupien PJ, Gagne C, et al. Treatment of familial hypercholesterolemia in children and adolescents: effect of lovastatin. Canadian Lovastatin in Children Study Group. Pediatrics. 1996;97(5): 619-628.

41. de Jongh S, Ose L, Szamosi T, et al. Efficacy and safety of statin therapy in children with familial hypercholesterolemia: a randomized, double-blind, placebo-controlled trial with simvastatin. Circulation 2002;106(17):2231-2237.

42. Hedman M, Matikainen T, Fohr A, et al. Efficacy and safety of pravastatin in children and adolescents with heterozygous familial hypercholesterolemia: a prospective clinical follow-up study. J Clin Endocrinol Metab. 2005;90(4):1942-1952.

43. Jones PH, Davidson MH, Stein EA, et al. Comparison of the efficacy and safety of rosuvastatin versus atorvastatin, simvastatin, and pravastatin across doses (STELLAR* Trial). Am J Cardiol. 2003;92(2):152-160

44. Avis HJ, Hutten BA, Gagne C, et al. Efficacy and safety of rosuvastatin therapy for children with familial hypercholesterolemia. J Am Coll Cardiol. 2010;55(11):1121-1126.

45. Heath KE, Gudnason V, Humphries SE, Seed M. The type of mutation in the low density lipoprotein receptor gene influences the cholesterollowering response of the $\mathrm{HMG}-\mathrm{CoA}$ reductase inhibitor simvastatin in patients with heterozygous familial hypercholesterolaemia. Atherosclerosis. 1999;143(1):41-54.

46. Arambepola C, Farmer AJ, Perera R, Neil HA. Statin treatment for children and adolescents with heterozygous familial hypercholesterolaemia: a systematic review and meta-analysis. Atherosclerosis. 2007;195(2):339-347.

47. Chui MC, Newby DE, Panarelli M, Bloomfield P, Boon NA. Association between calcific aortic stenosis and hypercholesterolemia: is there a need for a randomized controlled trial of cholesterol-lowering therapy? Clin Cardiol. 2001;24(1):52-55.

48. Gagne C, Gaudet D, Bruckert E. Ezetimibe study group. Efficacy and safety of ezetimibe coadministered with atorvastatin or simvastatin in patients with homozygous familial hypercholesterolemia. Circulation. 2002;105(21):2469-2475.

49. Ballantyne CM, Houri J, Notarbartolo A, et al. Effect of ezetimibe coadministered with atorvastatin in 628 patients with primary hypercholesterolemia: a prospective, randomized, double-blind trial. Circulation 2003;107(19):2409-2415.

50. Kastelein JJ, Akdim F, Stroes ES, et al. Simvastatin with or without ezetimibe in familial hypercholesterolemia. $N$ Engl J Med. 2008; 358(14):1431-1443.

51. Davidson MH, McGarry T, Bettis R, et al. Ezetimibe coadministered with simvastatin in patients with primary hypercholesterolemia. J Am Coll Cardiol. 2002;40(12):2125-2134.

52. Guyton JR, Brown BG, Fazio S, Polis A, Tomassini JE, Tershakovec AM. Lipid-altering efficacy and safety of ezetimibe/simvastatin coadministered with extended-release niacin in patients with type IIa or type IIb hyperlipidemia. J Am Coll Cardiol. 2008;51(16): 1564-1572.

53. Pijlman AH, Huijgen R, Verhagen SN, et al. Evaluation of cholesterol lowering treatment of patients with familial hypercholesterolemia: a large cross-sectional study in The Netherlands. Atherosclerosis. 2010; 209(1):189-194
54. Akdim F, Visser ME, Tribble DL, et al. Effect of mipomersen, an apolipoprotein B synthesis inhibitor, on low-density lipoprotein cholesterol in patients with familial hypercholesterolemia. Am J Cardiol. 2010;105(10):1413-1419.

55. Raal FJ, Santos RD, Blom DJ, et al. Mipomersen, an apolipoprotein B synthesis inhibitor, for lowering of LDL cholesterol concentrations in patients with homozygous familial hypercholesterolaemia: a randomised, double-blind, placebo-controlled trial. Lancet. 2010; 375(9719):998-1006.

56. Kolansky DM, Cuchel M, Clark BJ, et al. Longitudinal evaluation and assessment of cardiovascular disease in patients with homozygous familial hypercholesterolemia. Am J Cardiol. 2008;102(11): $1438-1443$

57. Julius U, Frind A, Tselmin S, Kopprasch S, Poberschin I, Siegert G. Comparison of different LDL apheresis methods. Expert Rev Cardiovasc Ther. 2008;6(5):629-639.

58. Szczepiorkowski ZM, Bandarenko N, Kim HC, et al. Guidelines on the use of therapeutic apheresis in clinical practice: evidence-based approach from the Apheresis Applications Committee of the American Society for Apheresis. J Clin Apher. 2007;22(3):106-175.

59. Thompson GR, Barbir M, Davies D, et al. Efficacy criteria and cholesterol targets for LDL apheresis. Atherosclerosis. 2010;208(2): 317-321.

60. Koga N, Watanabe K, Kurashige Y, Sato T, Hiroki T. Long-term effects of LDL apheresis on carotid arterial atherosclerosis in familial hypercholesterolaemic patients. J Intern Med. 1999;246(1): 35-43.

61. Beigel R, Beigel Y. Homozygous familial hypercholesterolemia: long term clinical course and plasma exchange therapy for two individual patients and review of the literature. J Clin Apher. 2009;24(6): 219-224.

62. Moghadasian MH, Frohlich JJ, Saleem M, Hong JM, Qayumi K, Scudamore CH. Surgical management of dyslipidemia: clinical and experimental evidence. J Invest Surg. 2001;14(2):71-78.

63. Bilheimer DW, Goldstein JL, Grundy SM, Starzl TE, Brown MS. Liver transplantation to provide low-density-lipoprotein receptors and lower plasma cholesterol in a child with homozygous familial hypercholesterolemia. N Engl J Med. 1984;311(26):1658-1664.

64. Lopez-Santamaria M, Migliazza L, Gamez M, et al. Liver transplantation in patients with homozygotic familial hypercholesterolemia previously treated by end-to-side portocaval shunt and ileal bypass. J Pediatr Surg. 2000;35(4):630-633.

65. East C, Grundy SM, Bilheimer DW. Normal cholesterol levels with lovastatin (mevinolin) therapy in a child with homozygous familial hypercholesterolemia following liver transplantation. JAMA. 1986; 256(20):2843-2848.

66. Alkofer BJ, Chiche L, Khayat A, et al. Liver transplant combined with heart transplant in severe heterozygous hypercholesterolemia: report of the first case and review of the literature. Transplant Proc. 2005;37(5):2250-2252.

67. Starzl TE, Bilheimer DW, Bahnson HT, et al. Heart-liver transplantation in a patient with familial hypercholesterolaemia. Lancet. 1984;1(8391):1382-1383.

68. Nemati MH, Astaneh B, Zamirian M. Aortic valve replacement in a patient with liver cirrhosis and coagulopathy. Gen Thorac Cardiovasc Surg. 2008;56(8):430-433.

69. Quinn DW Jr, Spinler SA. Efficacy of statins in preventing progression of aortic stenosis. Am J Health Syst Pharm. 2005;62(9): 979-981.

70. Pate GE, Tahir MN, Murphy RT, Foley JB. Anti-inflammatory effects of statins in patients with aortic stenosis. J Cardiovasc Pharmacol Ther. 2003;8(3):201-206.

71. Kastelein JJ. Screening for familial hypercholesterolaemia. Effective, safe treatments and DNA testing make screening attractive. BMJ 2000;321(7275):1483-1484. 
72. Bhatnagar D, Morgan J, Siddiq S, Mackness MI, Miller JP, Durrington PN. Outcome of case finding among relatives of patients with known heterozygous familial hypercholesterolaemia. BMJ. 2000;321(7275):1497-1500.

73. Wilson JM, Chowdhury JR. Prospects for gene therapy of familial hypercholesterolemia. Mol Biol Med. 1990;7(3):223-232.

74. Raper SE, Grossman M, Rader DJ, et al. Safety and feasibility of liver-directed ex vivo gene therapy for homozygous familial hypercholesterolemia. Ann Surg. 1996;223(2):116-126.

75. Kobayashi K, Oka K, Forte T, et al. Reversal of hypercholesterolemia in low density lipoprotein receptor knockout mice by adenovirus-mediated gene transfer of the very low density lipoprotein receptor. J Biol Chem. 1996;271(12):6852-6860.
76. Takahashi S, Ohsugi K, Yamamoto T, Shiomi M, Sakuragawa N. A novel approach to ex vivo gene therapy for familial hypercholesterolemia using human amniotic epithelial cells as a transgene carrier. Tohoku J Exp Med. 2001;193(4):279-292.

77. Hibbitt OC, McNeil E, Lufino MM, Seymour L, Channon K, Wade-Martins R. Long-term physiologically regulated expression of the low-density lipoprotein receptor in vivo using genomic DNA mini-gene constructs. Mol Ther. 2010;18(2):317-326.

\section{Publish your work in this journal}

Vascular Health and Risk Management is an international, peerreviewed journal of therapeutics and risk management, focusing on concise rapid reporting of clinical studies on the processes involved in the maintenance of vascular health; the monitoring, prevention and treatment of vascular disease and its sequelae; and the involvement of metabolic disorders, particularly diabetes. This journal is indexed on PubMed Central and MedLine. The manuscript management system is completely online and includes a very quick and fair peer-review system, which is all easy to use. Visit http://www.dovepress.com/ testimonials.php to read real quotes from published authors. 